ABA on the levels of circulating TFH-like cells of RA patients.

Methods: 25 RA patients ( $F / M=18 / 7$; median age (25th-75th percentile): 57 (4463) years; ACPA+: $16(64 \%)$; RF+: $17(68 \%))$, treated for at least 6 consecutive months with ABA were evaluated. Circulating TFH-like cells were identified by flow-cytometry as $\mathrm{CD} 4+\mathrm{ICOS}+\mathrm{CXCR} 5+$. The response to treatment was evaluated with the EULAR Criteria.

Results: After 6 months of therapy with $A B A$ the percentage of circulating TFH-like cells among total CD4+ T-cells tended to decrease from a median of $1.8(0.6-3.8)$ to $0.8(0.1-2.3)$ ( $p: 0.07$; Wilcoxon signed rank test). The percentage of circulating TFH-like cells at baseline was higher among patient who did not respond to $A B A$ (n.8; $2.6(2.0-3.6))$ than in those who achieved a moderate or good EULAR response ( $\mathrm{n}: 17 ; 1.0(0.5-5.4))(\mathrm{p}<0.01$; Mann-Whitney test), but their trend of reduction was similar in the two groups of patients. No difference in the levels of circulating TFH-like cells was found between ACPA+ and ACPA- RA patients.

Conclusions: ABA tends to reduce the number of circulating TFH-like cells in RA patients, suggesting the relevance of costimulation via CD28 in their generation. A higher percentage of these cells is present in patients not responding to ABA. While this observation suggests their possible use as predictors of clinical response to $A B A$, further studies are deserved to evaluate whether it reflects different localizations of TFH, or functional variability within this T-cell subset in patients with RA.

References:

[1] Koenders $\mathrm{M}$ et al, Arthritis Rheum 2012

[2] Airo' P et al, Arthritis Rheumatol 2015.

[3] Platt AL et al, J Immunol 2010.

[4] Iwata S et al, Arthritis Rheumatol 2015.

Acknowledgements: Bristol-Myers-Squibb Italy provided an unrestricted research grant for the study conduct and did not interfere with the conception and design of the study, acquisition, analysis, interpretation of data, and manuscript drafting.

Disclosure of Interest: None declared

DOI: 10.1136/annrheumdis-2017-eular.4081

\section{FRI0250 SERIOUS ADVERSE EVENTS IN PATIENTS WITH RA TAKING ABATACEPT COMPARED WITH OTHER DMARDS BY LINE OF TREATMENT}

S.A. Pedro ${ }^{1}$, R. Schumacher ${ }^{1}$, K. Michaud ${ }^{1,2},{ }^{1}$ National Data Bank for Rheumatic Diseases, Wichita, KS; ${ }^{2}$ University of Nebraska Medical Center, Omaha, NE, United States

Background: Observational studies are critical in assessing medication safety and effectiveness in the real world. Nonrandom assignment can provide insight to how and when medications are prescribed. Since the US introduction of TNF inhibitors (TNFi) in 1998, several newer biologics with varying mechanisms of action are available to patients and physicians.

Objectives: To compare baseline characteristics and serious adverse events (serious infections (SI), malignancies) of patients who received abatacept (ABA) compared to those who received other comparison cohorts: conventional DMARDs (cD) and biologic DMARDs (bD) by line of treatment.

Methods: Participating patients from 2005-2015 with RA in the National Data Bank for Rheumatic Diseases (NDB) provided treatment and other characteristics through self-reported biannual questionnaires. Initiators of ABA were matched to patients initiating other DMARDs in a 1:3 ratio. All patient-reported outcomes were verified by medical record review. ITT (OT) analyses were performed for malignancies (SI). Incidence rates were calculated using Poisson regression (1000 patients-years (pt-yr)). Marginal structural models were used to estimate the effect of treatment on the outcome by an appropriate control for the effects of time-dependent confounders using stabilized weights and reported as hazard ratios (HR). Variables included sex, employment, smoking, education, income, BMI, insurance, comorbidity index, RA severity, and co-medications.

Results: Overall 1496 ABA patients with 2502 (4896) pt-yr of drug exposure (total follow-up time), $1520 \mathrm{cD}$ treated patients with $4330 \mathrm{pt}-\mathrm{yr}$ of drug exposure (4816) and $3490 \mathrm{bD}$ treated patients with $9658 \mathrm{pt}-\mathrm{yr}$ of drug exposure (11777) were studied (overall mean age 62 years (83\% female)). At baseline, the distribution of first line patients in the several cohorts was: $15.2 \%$ ABA, for $23.4 \%$ bD and $33.8 \% \mathrm{cD}$. Switchers were more likely to have longer duration of RA (mean values (yrs): 11.4 for ABA, $8.3 \mathrm{cD} ; 14.7 \mathrm{bD}$ first line vs. 17.6 ABA; $17.4 \mathrm{cD} ; 18.0 \mathrm{bD}$ switchers), higher comorbidities, including prior cancer. ABA patients had worse disease compared to $\mathrm{cD}$ or $\mathrm{bD}$, both used as first line or as switchers (mean HAQ any line for $A B A 1.3$ vs 1.0 (1.2) cD or 1.0 (1.3) bD as first line or as switchers).

Table 1. Incidence rates of malignancies and SI for $3 \mathrm{RA}$ treatment cohorts by line of treatment

\begin{tabular}{cccc}
\hline & $\mathrm{ABA}$ & $\mathrm{CD}$ & $\mathrm{bD}$ \\
\hline All malignancies & & & \\
0 & $8.2(1.7-23.9)$ & $8.2(4.8-13.1)$ & $5.1(2.8-8.5)$ \\
1 & $6.3(2.3-13.7)$ & $11.8(4.3-25.7)$ & $5.0(2.2-9.8)$ \\
$\mathrm{SI}^{2+}$ & $8.3(4.4-14.3)$ & $4.5(0.1-25.2)$ & $4.7(1.5-11.0)$ \\
0 & & & \\
1 & $3.0(0.1-16.6)$ & $15.3(11.2-20.5)$ & $15.1(11.4-19.5)$ \\
$2+$ & $17.9(10.0-29.6)$ & $27.2(16.9-41.6)$ & $18.6(13.4-25.1)$ \\
\hline
\end{tabular}

Excluding patients with prior events, incidence rates of malignancies tended to be uniform by line of treatment but SI seemed to increase with higher exposure of prior biologics, in all cohorts (Table). HR estimates by MSM did not show an increased risk for ABA in comparison with both cohorts, irrespectively of the line of treatment considered.

Conclusions: Differences in baseline characteristics revealed that channeling bias might be present when comparing ABA with other DMARDs and by line of treatment. After adjustment, no overall risk was found for increased risk of cancer and infections.

Disclosure of Interest: S. Pedro Employee of: National Data Bank for Rheumatic Diseases, R. Schumacher Employee of: National Data Bank for Rheumatic Diseases, K. Michaud Employee of: National Data Bank for Rheumatic Diseases DOI: 10.1136/annrheumdis-2017-eular.6357

\section{FRI0251 SIRUKUMAB, AN ANTI-IL-6 CYTOKINE MONOCLONAL ANTIBODY, LEADS TO IMPROVEMENTS IN WORK PRODUCTIVITY AND GENERAL HEALTH STATUS IN PATIENTS WITH ACTIVE RHEUMATOID ARTHRITIS REFRACTORY TO ANTI-TNF THERAPY: RESULTS FROM THE PHASE 3 SIRROUND-T STUDY}

Y. Tanaka ${ }^{1}$, D. Aletaha ${ }^{2}$, S. Peterson ${ }^{3}$, R. Ganguly ${ }^{4}$, R. Kurrasch ${ }^{4}$, S. Popik ${ }^{3}$ P. Agarwal ${ }^{3}, \mathrm{~N} . \mathrm{Li}^{3} .{ }^{1}$ University of Occupational \& Environmental Health, Kitakyushu, Japan; ${ }^{2}$ Division of Rheumatology, Medical University of Vienna, Vienna, Austria; ${ }^{3}$ Janssen Research \& Development, LLC, Spring House, PA ${ }^{4}$ GlaxoSmithKline, Collegeville, PA, United States

Background: Sirukumab is an anti-interleukin-6 (IL-6) monoclonal antibody that selectively binds to the cytokine with high affinity and is in development for rheumatoid arthritis (RA) and other diseases.

Objectives: This study evaluated the effects of sirukumab on work productivity/interference and health status in patients with active RA despite treatment with anti-tumor necrosis factor (TNF) therapy.

Methods: In this randomized, double-blind, phase 3 trial, 878 eligible patients with active RA who were intolerant/refractory to anti-TNFs were randomized 1:1:1 to sirukumab subcutaneous (SC) 50 mg every 4 weeks ( $q 4 w ; n=292)$, sirukumab SC $100 \mathrm{mg}$ every 2 weeks (q2w; $n=292)$, or placebo SC q2w $(n=294)$. At Week 18, placebo patients were re-randomized to 1 of the sirukumab doses if insufficient $(<20 \%)$ improvement; at Week 24 , all patients remaining on placebo crossed over to sirukumab. The Work Limitations Questionnaire (WLQ) evaluated health-related job limitations and productivity loss in 4 domains (mental-interpersonal, output, physical demands, time management); the 3-level EuroQol-5 Dimension (EQ-5D) questionnaire measured 5 dimensions of health status (mobility, self-care, usual activities, pain/discomfort, anxiety/depression).

Results: At Week 24, mean total WLQ scores improved significantly from baseline for sirukumab $50 \mathrm{mg} \mathrm{q4}$ w and $100 \mathrm{mg}$ q2w versus placebo (mean change, -2.2 and -2.3 vs 0.2 , respectively; both $p<0.001$ ), as did all 4 mean WLQ domain scores (all $p \leq 0.01$ ). Improvements from baseline in mean total WLQ and all 4 domain scores were maintained through Week 52 for both sirukumab doses. Mean EQ-5D index and health state visual analog scale (VAS) scores improved significantly from baseline at Week 24 for sirukumab 50mg q4w and 100mg q2w versus placebo (mean index change, 0.2 and 0.2 vs 0.0 , respectively; mean VAS change, 13.9 and 15.4 vs 4.8 , respectively; all $p<0.001$ ); improvements from baseline were maintained through Week 52 with both sirukumab doses.

Conclusions: Sirukumab treatment led to significant improvements in workrelated productivity and general health status in patients with active RA despite anti-TNF therapy, consistent with demonstrated effects of sirukumab on RA disease improvement.

Disclosure of Interest: Y. Tanaka Grant/research support from: Abbvie, Astellas, Bristol-Myers, Chugai, Daiichi-Sankyo, Eisai, Mitsubishi-Tanabe, MSD, Takeda Speakers bureau: Abbvie, Asahi Kasei, Astellas, Bristol-Myers, Chugai, DaiichiSankyo, Eli Lilly, GlaxoSmithKline, Janssen, Mitsubishi-Tanabe, Pfizer, Sanofi, Takeda, Teijin, YL Biologics, D. Aletaha Grant/research support from: Abb Vie, Pfizer, Grünenthal, Merck, Medac, UCB, Mitsubishi/Tanabe, Janssen, and Roche, Consultant for: AbbVie, Pfizer, Grünenthal, Merck, Medac, UCB, Mitsubishi/Tanabe, Janssen, and Roche, S. Peterson Shareholder of: Janssen Research \& Development, LLC, Employee of: Janssen Research \& Development, LLC, R. Ganguly Shareholder of: GlaxoSmithKline, Employee of: GlaxoSmithKline, R. Kurrasch Shareholder of: GlaxoSmithKline, Employee of: GlaxoSmithKline, S. Popik Shareholder of: Janssen Research \& Development, LLC, Employee of: Janssen Research \& Development, LLC, P. Agarwal Shareholder of: Janssen Research \& Development, LLC, Employee of: Janssen Research \& Development, LLC, N. Li Shareholder of: Janssen Research \& Development, LLC, Employee of: Janssen Research \& Development, LLC

DOI: 10.1136/annrheumdis-2017-eular.3597 